\title{
Carolus: um novo sistema gratuito para manipulação eletrônica de coleções botânicas
}

\author{
Carolus: A new system for handling electronic botanical collections
}

\author{
Alisson Amorim Siqueira ${ }^{1}$, José Valentim dos Santos Filho ${ }^{3}$ \& José Alves de Siqueira Filho ${ }^{1,2,4}$
}

\begin{abstract}
Resumo
Este estudo descreve um novo sistema para manipulação e gerenciamento eletrônico de coleções botânicas. O software descrito foi desenvolvido com objetivo de auxiliar herbários brasileiros no resgate e manutenção segura de registros de espécies de plantas provenientes de diversos ecossistemas nacionais, fornecendo uma ferramenta confiável, com interface amigável, fácil de utilizar e dotado de funcionalidades para cadastro, consultas, atualizações, estatísticas, relatórios, geração de etiquetas, geoprocessamento e banco de imagens. Palavras-chave: banco de dados, coleções botânicas, botânica aplicada.
\end{abstract}

\begin{abstract}
This study describes a new system for handling and eletronic managing of botanical collections. The software described here was developed in order to give support to herbaria in the task of protecting records of plants species from various national ecosystems, by providing a safe tool, with a friendly interface, easy to use and equipped with features for registration, consultation, updates, statistics, reports, label management, geoprocessing and image database.
\end{abstract}

Key words: databases, botanical collection informatization, applied botany

\section{Introdução}

Muito mais do que uma coleção científica compostas por plantas desidratadas, os herbários desempenham um papel único e crítico diante dos esforços globais em amenizar a perda da biodiversidade (Schatz 2002), sustentando um inestimável acervo de plantas e dados que documentam a existência de espécies em um determinado tempo e espaço.

As informações contidas em um herbário representam fontes básicas para estudos taxonômicos, florísticos e ecológicos, além de subsidiar trabalhos de biodiversidade, usos medicinais, tóxicos, forrageiros e indústria alimentícia em geral (Barbosa \& Peixoto 2003; Peixoto et al. 2009).

Diante desta inquestionável importância, fica evidente a necessidade por métodos organizados e sistemáticos de armazenamento e processamento dos dados coletados (Walters 1993; Heywood 2001).

Essa organização tornou-se possível com o grande desenvolvimento das tecnologias de informação nas últimas duas décadas, permitindo a criação e gerenciamento eficiente de bancos de dados de grande porte, transformando dados em informação e, por sua vez, a informação em conhecimento para tomada de decisões críticas (Teixeira et al. 1992).

Apesar do grande volume de informações geradas diariamente em todas as áreas do conhecimento humano, os dados coletados são importantes apenas quando se consegue classificá-los e organizá-los, tornando-os úteis para pesquisadores e instituições. Este fato torna um banco de dados um dos componentes

\footnotetext{
${ }^{1}$ Centro de Referência para a Recuperação de Áreas Degradadas da Bacia Hidrográfica do Rio São Francisco, Bioma Caatinga (CRAD/UNIVASF) - Campus Ciências Agrárias, BR 407, km 12, lote 543, Distrito de Irrigação Senador Nilo Coelho, 56300-990, Petrolina, PE.

${ }^{2}$ Colegiado de Ciências Biológicas, Campus Ciências Agrárias, BR 407, km 12, lote 543, Distrito de Irrigação Senador Nilo Coelho, 56300-990, Petrolina, PE.

${ }^{3}$ Centro de Ciências Exatas e Tecnológicas, Universidade Federal do Recôncavo da Bahia, 44380-000, Cruz das Almas, BA.

${ }^{4}$ Autor para correspondência: jose.siqueira@univasf.edu.br
} 
essenciais de uma empresa ou instituição (Roeldes et al. 2009).

No manejo do herbário, a importância dos bancos de dados não é diferente, muito pelo contrário, agregam-se outras dificuldades e desafios, como integração com Sistemas de Informações Geográficas (SIGs), mecanismo de compatibilidade com softwares já existentes, ferramentas de auxílio à identificação de espécies, análises estatísticas, sistemas automatizados de geração e atualização de etiquetas, relatórios, gráficos e, principalmente, a necessidade de publicar via web os dados armazenados, permitindo fácil acesso a qualquer usuário com conexão à internet.

Apesar da popularização dos sistemas de informação em todo mundo, a grande maioria dos herbários no Brasil não têm suas coleções completamente informatizadas, enfrentando problemas semelhantes ao tentar iniciar este processo, ou como é comum, não conseguindo iniciar sua informatização (Peixoto et al. 2009). A baixa disponibilidade de softwares específicos para este objetivo, as dificuldades de instalação, utilização e manutenção destes programas, juntamente com o grande investimento em recursos materiais e humanos aplicados nesta tarefa, sem qualquer garantia de retorno, tornam a informatização de herbários uma tarefa lenta, arriscada e cara, quando não inviabilizam todo o processo (Peixoto 2005).

Assim, os objetivos deste estudo foram: 1) analisar o nível de informatização dos herbários brasileiros, através da Rede Brasileira de Herbários; 2) analisar os aspectos funcionais e tecnológicos dos principais bancos de dados utilizados no Brasil; 3) propor uso e disseminação do software Carolus como ferramenta de apoio às coleções botânicas no Brasil, fornecendo aos herbários brasileiros um programa fácil de usar e instalar, com interface amigável e intuitiva, seguro, com alta escalabilidade e gratuito.

\section{Material e Métodos}

Com intuito de analisar o nível de informatização dos herbários brasileiros, foram realizadas consultas em artigos científicos e na base de dados da Rede Brasileira de Herbários (<http://www.botanica.org.br/rede_ herbarios.php $>$ ) pelos softwares utilizados para informatização das coleções nacionais.

Após a coleta dos dados, registrou-se os softwares mais utilizados pelos herbários e as ferramentas disponíveis nesses softwares, para posterior comparação dos programas identificados e avaliação da possibilidade de uso na informatização de coleções brasileiras. As informações presentes neste trabalho referem-se às versões encontradas enquanto o manuscrito estava sendo redigido. As palavras software, sistema e aplicativo foram utilizadas indistintamente como sinônimos de programa computacional.

O desenvolvimento do software Carolus teve início com a adoção do PostgreSQL 8, um Sistema Gerenciador de Banco de Dados (SGBD). Um SGBD pode ser concebido como um conjunto de programas que armazenam, organizam e recuperam informações, fornecendo segurança, desempenho e diversas características desejáveis à manipulação de dados, como a possibilidade de diversos usuários acessarem registros simultaneamente (Heuser 2009).

A escolha pelo PostgreSQL 8 é justificada por se tratar de um projeto maduro, com mais de 15 anos de desenvolvimento ativo, totalmente gratuito e ostentar o título de mais poderoso e avançado banco de dados Open Source do mundo, podendo ser utilizado em projetos que demandem segurança, desempenho e grande capacidade de armazenamento (<www.postgresql.org $>$ ).

Após a adoção do SGBD, as tabelas (conjunto de campos que representam e descrevem as características de um modelo ou objeto do mundo real) e as restrições de relacionamento dos campos foram modeladas e armazenadas no Postgresql. Esta modelagem foi cuidadosamente estabelecida com base em experiências de informatização de herbários nacionais (Peixoto 2005). O conjunto de campos foi escolhido para permitir que as informações importantes referentes ao material coletado fossem cadastradas da maneira mais organizada, sistemática e genérica possível, permitindo a utilização do sistema desenvolvido em outros herbários e evitando um número abusivo ou subutilizado de campos.

Com a base de dados modelada, diversos testes foram efetuados para verificar se as restrições de relacionamento estavam sendo 
atendidas. As restrições são responsáveis por impedir, por exemplo, o cadastro de números de tombo ou número de coleta repetidos, manter o controle de acesso e atualizações de registros para recuperações de erros, além de toda a consistência das informações registradas (Silberschatz et al. 1999).

Finalizados a implementação e os testes no banco de dados, teve início o desenvolvimento do aplicativo para comunicação com o banco, que representa o produto final para o usuário, o software propriamente dito, o qual torna transparente ao usuário toda a manipulação eletrônica dos dados no PostgreSQL (Pressman 2002). No modelo do fluxo de dados do software Carolus cada computador representa um usuário (Fig. 1).

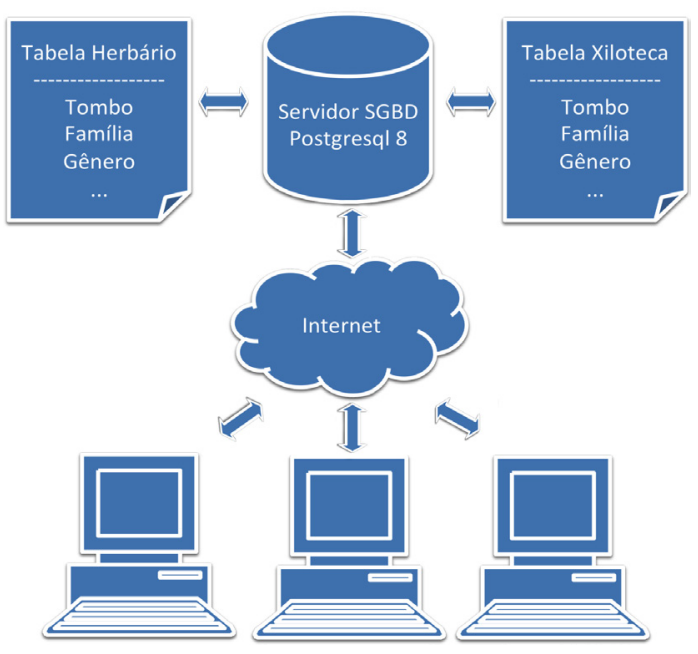

Figura 1-Modelo do fluxo de dados do software Carolus. Através de um ou mais computadores conectados à internet é possível acessar o servidor com o Postgresql, inserindo, consultado ou atualizado dado nas tabelas que abstraem o armazenamento de informações das coleções científicas. As setas em duas direções indicam que o fluxo de dados pode ser de entrada ou saída e por estar centralizado em um servidor, todos os computadores trabalham simultaneamente, como se estivesse acessando o mesmo arquivo sem provocar inconsistências.

Figure 1 - Carolus's Data flow model. Using one or more computers connected to the internet, it's possible to access the server with PostgreSQL, inserting, query or update data in tables, which abstract the storage of informations from scientific collections. The two-ways arrows indicate that flow of data can be input or output and because it's centralized in one server, all computers work together, as if you were accessing the same file without creating inconsistencies.
Para testar a escalabilidade do banco e do sistema desenvolvido, isto é, a capacidade continuar funcionando independente da carga de trabalho, 20 milhões de registros com valores aleatórios foram inseridos automaticamente na base de dados. Com o banco povoado de registros, foram executadas consultas por dados específicos, por exemplo, um intervalo de números de tombos ou a porcentagem das famílias mais representativas de uma determinada região, com o objetivo de verificar se a velocidade de resposta do banco de dados continuava com a rapidez aceitável de no máximo quatro segundos e se o programa não apresentava travamento ou falhas por conta do aumento de recursos computacionais exigidos, mantendo sua estabilidade e robustez.

A implementação do software foi realizada através da linguagem de programação $\mathrm{C}++$, que utiliza o paradigma de programação orientado a objetos (Deitel \& Deitel 2001). Esta linguagem é responsável pela construção dos sistemas operacionais modernos, como Windows ${ }^{\mathrm{TM}}$ e Linux, além de apresentar grande desempenho e alta velocidade de execução. O desenvolvimento do programa ocorreu no sistema operacional Windows para permitir que programa seja instalado sem necessidades externas e mantendo alta compatibilidade com as diferentes versões do Windows ${ }^{\mathrm{TM}}$, podendo ainda ser executado em outros sistemas operacionais, como distribuições Linux.

Posteriormente, foram adicionadas ferramentas e funcionalidades para o processamento de dados, como Sistema de Informações Geográficas (SIG), geração avançada de gráficos, etiquetas e relatórios, funcionalidade para importação, exportação, backup, atualizações em massa de informações, sistemas de identificação de espécies e banco de imagens.

Para atender ao cadastro de diferentes tipos de dados, adicionou-se ao aplicativo diversos módulos para entrada de informações de outras coleções botânicas, como coleção de madeiras, de sementes e de plantas vivas. Cada módulo tem suas características próprias para melhor lidar com as particularidades do material coletado. 


\section{Resultados e Discussão}

Segundo os dados disponíveis em 2010 na Rede Brasileira de Herbários ( $<$ http://www. botanica.org.br/rede herbarios.php $>$ ) (Fig. 2) dos 179 herbários brasileiros indexados no site, $56 \%$ deles não possui qualquer sistema de informatização (100 herbários), 8\% declararam estar em processo de informatização (14 herbários), mas não citam quais softwares estão utilizando para este fim, 5\% utilizam softwares desenvolvidos nas próprias instituições (9 herbários), $10 \%$ utilizam Access ${ }^{\circledR}$ ou Excel $^{\circledR}$ como sinônimo de informatização (18 herbários) e $21 \%$ utilizam o $B R A H M S$ como programa para cadastro dos dados coletados (38 herbários). Estas informações agravam os números apontados por Peixoto (2005) tornando urgente a necessidade de investimento em softwares aplicado no controle eletrônico de informações botânicas. As características operacionais dos softwares mais comuns no Brasil são comparados com Carolus (Tab. 1).

Utilizados em vários herbários brasileiros como ferramenta para informatização, o Microsoft Excel ${ }^{\circledR}$ e o Microsoft Access ${ }^{\circledR}$ não deveriam ser utilizados como sinônimo para esta atividade, uma vez que estes softwares apresentam reduzida escalabilidade (i.e., capacidade de aumentar o número de dados e continuar funcionado com a mesma eficiência), exigem treinamento para utilização efetiva das capacidades de processamento, possuem

\section{Situação dos Herbário Brasileiros em Março de 2010}

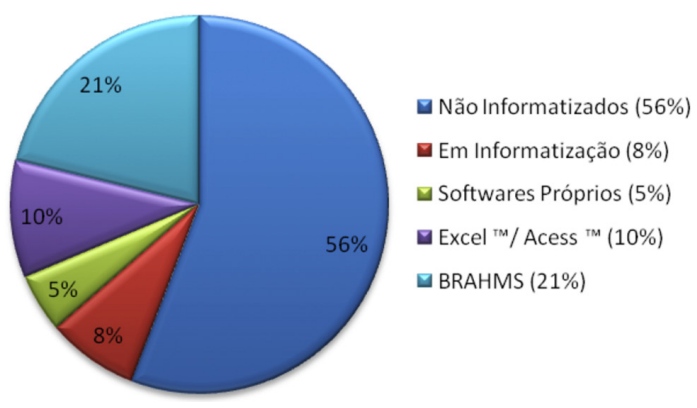

Figura 2 - Informatização dos herbários brasileiros, segundo a Rede Brasileira de Herbários.

Figure 2- Brazilian herbaria informatization of its collections, according to Rede Brasileira de Herbários. baixa segurança para os dados, dependências de sistema operacional, limitações quanto à quantidade de usuários simultâneos, baixa integração com outras ferramentas e o elevado custo de aquisição. (Fig. 3).

O BRAHMS, Botanical Research and Herbarium Management System, é um software desenvolvido pela Universidade de Oxford (Inglaterra), conhecido como o programa de gerenciamento de coleções botânicas mais utilizadas no mundo, sendo também um dos mais completos, em termos de recursos e ferramentas. No site do programa é possível encontrar a documentação completa de suas funcionalidades $(<\mathrm{http}: / /$ dps.plants.ox.ac.uk/bol/>). Entretanto, o software é de difícil instalação, por questões de registro e aquisição de chaves, possui uma interface pouco amigável, exige considerável treinamento para uma utilização razoável de seus recursos, requer conhecimentos avançados de informática e banco de dados para sua instalação e configuração online, possui um tamanho limitado para base de dados, a estrutura de diretórios e de arquivos é complexa, o programa é relativamente lento, mesmo quando funciona na versão offline e não conta com Sistema de Informações Geográfica integrado, apenas gera arquivos que diminuem o trabalho de quem vai utilizar ferramentas como Diva Gis $^{\circledR}$ ou ArcView ${ }^{\circledR}$. O programa BRAHMS é altamente configurável, o que permite sua adaptação com diferentes herbários, contudo, configurar o software corretamente para obter resultados desejados, demanda tempo e treinamento (Figs. 4-5).

O Herbário do Departamento de Ciências Florestais (HDCF), da Universidade Federal de Santa Maria, Rio Grande do Sul, desenvolveu o software Nature $2.0(<\mathrm{http}: / / \mathrm{w} 3 . \mathrm{ufsm}$. $\mathrm{br} /$ herbarioflorestal/nature/site/ $>$ ), como alternativa para herbários brasileiros que buscam facilidade e simplicidade no cadastro de dados. O software destaca-se pela facilidade de instalação e pela possibilidade de importar e exportar dados em vários formatos, inclusive no padrão internacional Darwin Core, e por possuir diversos módulos para tratamento de dados de exsicatas, xiloteca e carpoteca, por exemplo. Por outro lado, o Nature 2.0 é bastante limitado quanto a quantidade de recursos e 
configurações, suas ferramentas ainda não tem utilidade prática e o conjunto de campos não é genérico para permitir a adoção em herbários com diferentes particularidades (Fig. 6).

O programa Herbário 2.0 é uma alternativa nacional elaborado pela Universidade Estadual de Feira de Santana (UEFS). Este programa possui formulários para cadastro de registros com mais de 40 campos, com dados que vão desde informações taxonômicas e geográficas, até dados de controle do interno do herbário, tornando o software adequado ao uso em diferentes herbários, entretanto, o elevado número de campos desse programa aumenta o tempo de cadastro dos registros e intimida os usuários com formulários subutilizados. As maiores limitação deste software são a interface gráfica pouco amigável, o ambiente difícil de utilizar, a falta de manutenção do programa e a baixa escalabilidade, isto é,

Tabela 1 - Características de alguns softwares utilizados por herbários brasileiros.

Table 1 - Features of some softwares utilized by Brazilian herbaria.

\begin{tabular}{|c|c|c|c|c|}
\hline Características* & Carolus & BRAHMS & Herbário 2.0 & Jabot \\
\hline Banco de dados & Postgresql & Visual FoxPro & Access & Postgresql \\
\hline Facilidade de configuração & Sim & Não & Não & Sim \\
\hline Alta curva de aprendizado & Sim & Não & Não & Sim \\
\hline Interface amigável & Sim & Não & Não & Sim \\
\hline Diversos módulos & Sim & Sim & Não & Sim \\
\hline Cadastro facilitado & Sim & Não & Não & Sim \\
\hline Consultas avançadas & Sim & Sim & Não & Sim \\
\hline Etiquetas fácil & Sim & Não & Sim & $\operatorname{Sim}$ \\
\hline Formatação de etiquetas & Não & Sim & Não & Não \\
\hline Suporta outras ferramentas & Sim & Sim & Não & Sim \\
\hline Banco de imagens & Sim & Sim & Sim & Sim \\
\hline Facilidade para uso online & Sim & Não & Não & Sim \\
\hline Importação / Exportação & Sim & Sim & Não & Sim \\
\hline Consulta de imagens & Sim & $\operatorname{Sim}$ & Não & Sim \\
\hline SIG integrado & Sim & Não & Não & Não \\
\hline Versão Portátil & Sim & Não & Não & Não \\
\hline Banco de dados com GIS & Sim & Sim & Não & Não \\
\hline Identificação de espécies & Sim & Não & Não & Não \\
\hline Atualização em massa & $\operatorname{Sim}$ & $\operatorname{Sim}$ & Não & Não \\
\hline Suporte multilíngüe & Não & Sim & Não & Não \\
\hline Banco de DNA & Não & $\operatorname{Sim}$ & Não & Sim \\
\hline Ferramentas Web & Sim & Não & Não & Sim \\
\hline Disponível para download & Sim & Sim & Não & Não \\
\hline
\end{tabular}

Microsoft Excel $^{\circledR}$ e o Microsoft Access ${ }^{\circledR}$ não foram considerados nesta análise, para maiores informações vide o texto. 


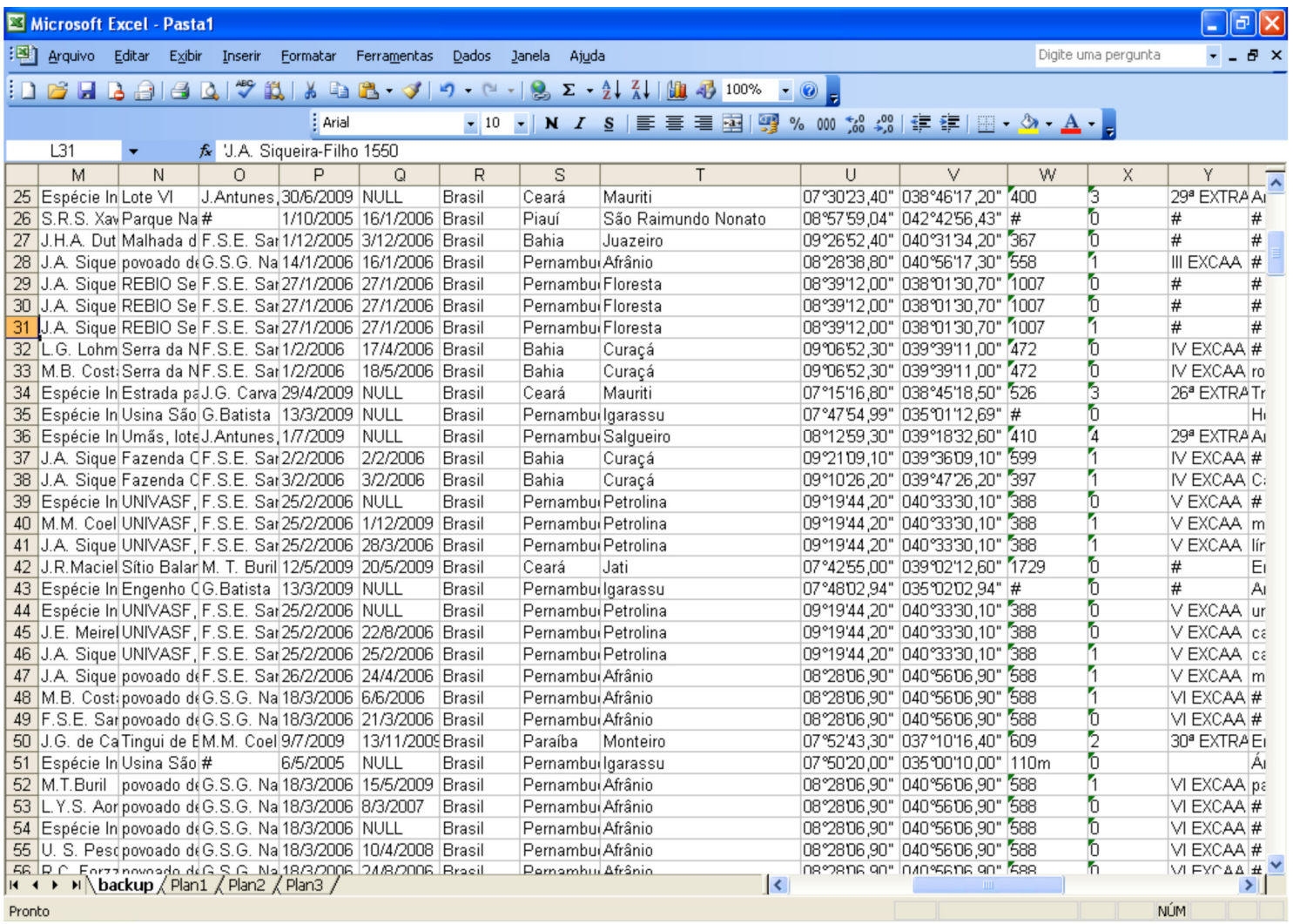

Figura 3 - Banco de dados em Excel $^{\circledR}$. Nota-se a dificuldade de localizar Registros, obter dados e visualizar erros. A falta de integração com outras ferramentas é outro fator negativo.

Figure 3 - Database in Excel ${ }^{\circledR}$. Note the difficulty of locating records, retrieve data and display errors. The lack of integration with other tools is another negative factor.

quanto mais registros são armazenados, mais lenta é a resposta do software, por utilizar uma versão antiga do Microsoft Access ${ }^{\circledR}$ ao invés de um moderno Sistema Gerenciador de Banco de Dados.

Outro software de origem nacional, o JABOT é um programa desenvolvido pelo Instituto de Pesquisas do Jardim Botânico do Rio de Janeiro para tornar-se o sistema de informatização do Herbário RB, um dos maiores do País. Desde 2005 este aplicativo permite consultas via internet na base de dados do Jardim Botânico (<http://www.jbrj.gov.br/ jabot $>$ ), como ilustra a Figura 7. O programa JABOT destaca-se pela sua robustez, com cerca de 500.000 exsicatas de plantas cadastradas, pelo suporte a diversas bases de dados, com banco de DNA e Xiloteca, por fornecer funções para administração do herbário, geração de relatórios, entre diversos outros aspectos. A Figura 8 mostra o formulário de entrada de dados do JABOT (Gonzalez 2009). O cadastro é facilitado e a interface é intuitiva para o usuário. Porém, não é possível, por este formulário, cadastrar imagens e nem auto-completar dados com as coordenadas geográficas do local de coleta do registro. Os nomes dos determinadores conferem credibilidade à identidade do táxon em estudo, porém, no site do JABOT alguns nomes de determinadores presentes nos registros cadastrados não obedecem a um padrão de nomenclatura, isto é, um determinador pode ser digitado de várias formas, sem um mecanismo de prevenção ou correção de erros de digitação, gerando incongruências em pesquisas e relatórios.

Nomeado em homenagem ao botânico sueco Carolus Linnaeus - criador da nomenclatura 


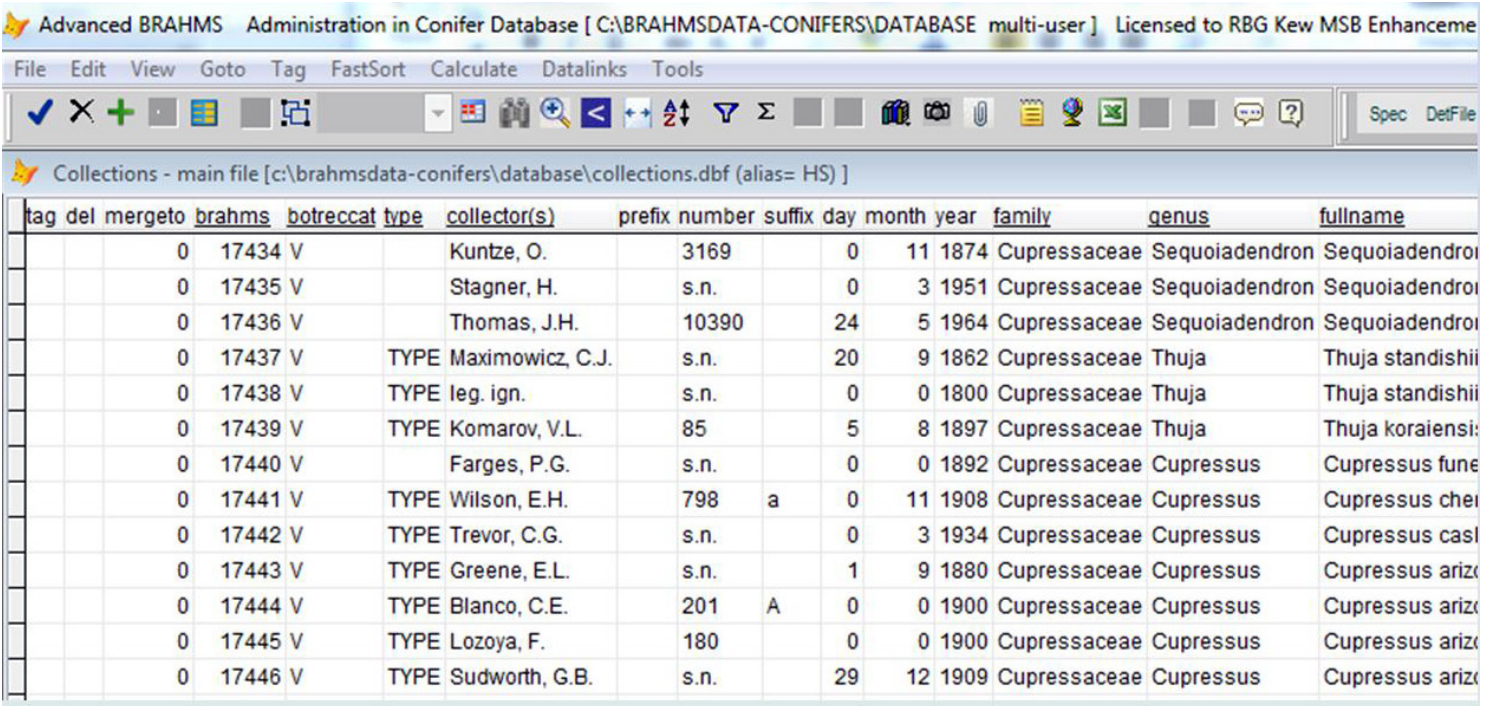

Figura 4 - Interface de entrada de dados genérica do BRAHMS 6.7. Os dados das coleções são exibidos em tabelas que aceitam filtros e condições de agrupação. Outros dados, como base de espécies, DNA e usuários são editadas da mesma forma. O gerenciamento de atividades no BRAHMS requer treinamento e bastante estudo. É difícil visualizar um registro em específico com recursos visuais, como mapas e imagens.

Figure 4 - BRAHMS 6.7's generic Interface Data Entry. The data collections are displayed in tables that accept filters and grouping conditions. Other data, like species, DNA, and users databases are edited the same way. The management of activities in the BRAHMS requires training and plenty of study. It is difficult to see one record in particular, with maps e images.

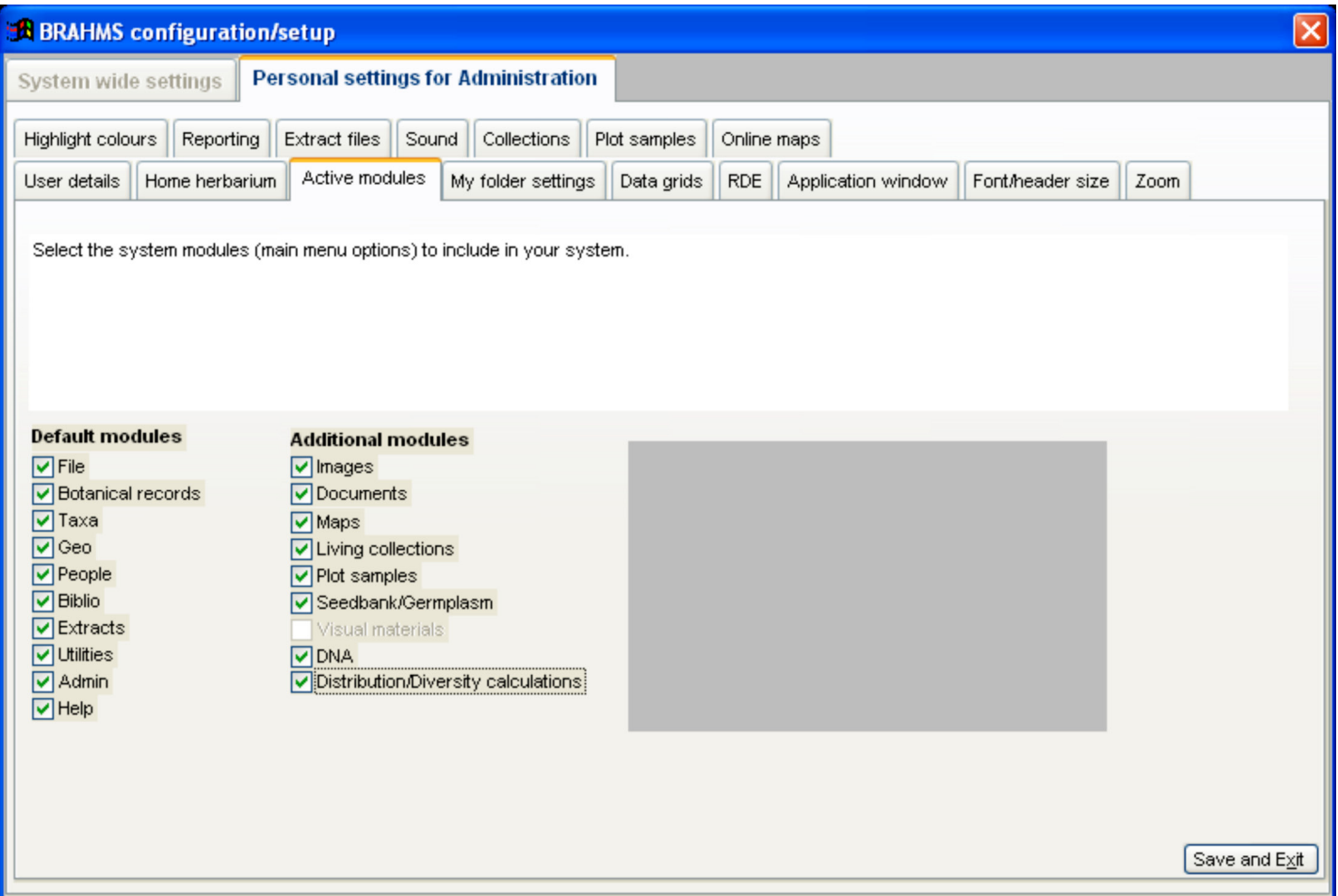

Figura 5 - Formulário de configuração do administrador no BRAHMS. Através dele é possível configurar o software como desejado. A imagem mostra a inclusão de módulos no programa, atendendo praticamente a todas as necessidades do herbário. Figure 5 - Administrator's Form Configuration in BRAHMS. Through it you can configure the software as desired. The image shows the inclusion of modules in the program, given almost all the needs of the herbarium. 


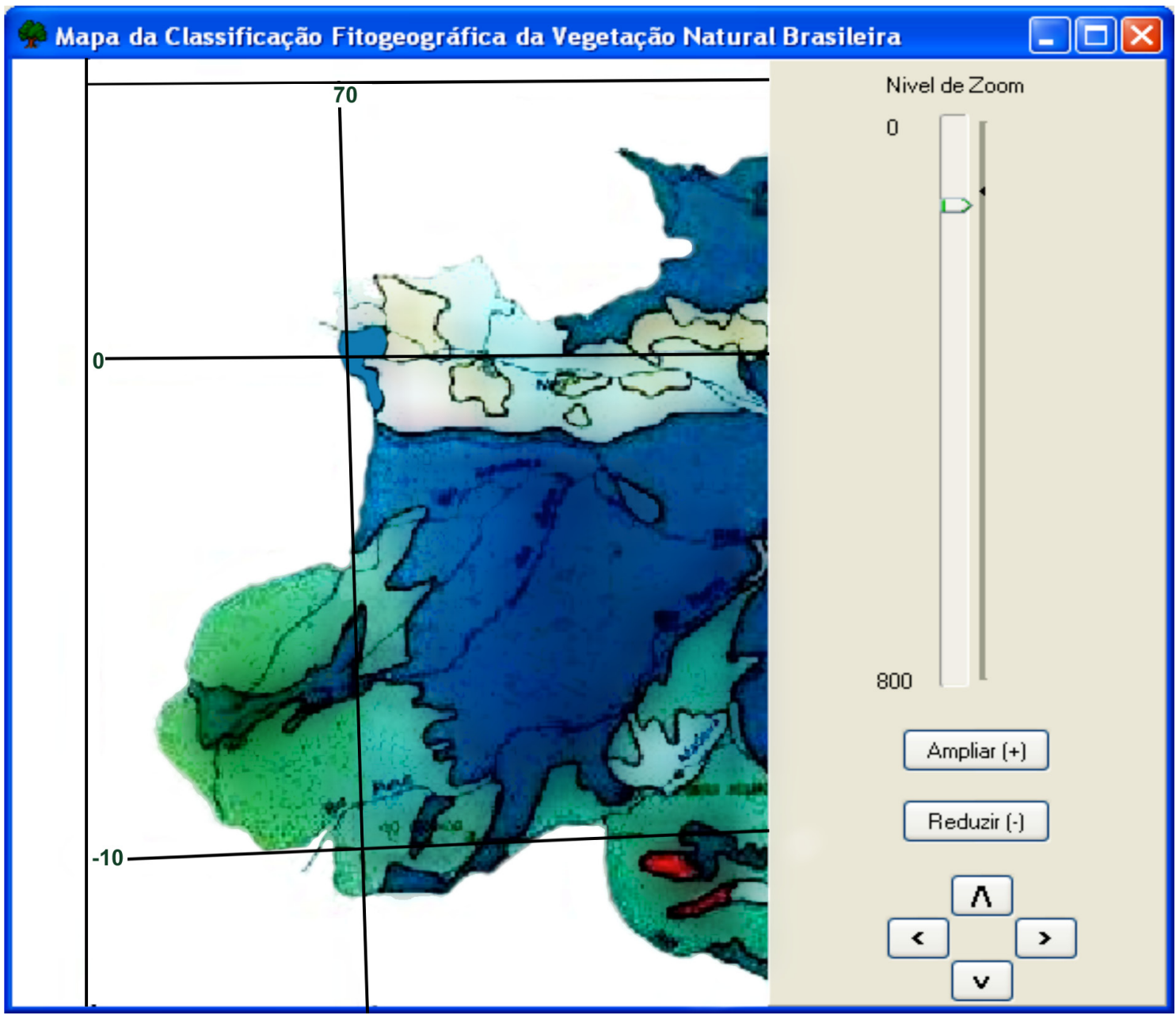

Figura 6 - Ferramentas do Sistema Nature 2. O software oferece vários recursos interessantes durante o cadastro e consulta de dados. As ferramenta presente, entretanto, são de baixa utilidade. Em anexo um mapa para determinada região de coleta, onde não é possível distinguir nenhum aspecto importante.

Figure 6 - Nature 2's Tools. The software offers various interesting feature during the registration and query data. The present tool, however, are of low utility. Attached a map for a region of collection, where is not possible distinguish any significant respect.

binomial e "pai da taxonomia", o software Carolus, registrado na Revista da Propriedade Industrial No 2044, processo 10370-4 (Siqueira et al. 2010), foi desenvolvido com o intuito de fornecer aos herbários brasileiros um programa fácil de instalar, com interface amigável e intuitiva, de aprendizado rápido, seguro, com alta escalabilidade e dotado de recursos para geoprocessamento, estatísticas, relatórios, geração automática de etiquetas e gráficos, manutenção e atualização de extensos volumes de dados, sendo totalmente gratuito (Fig. 9). A principal funcionalidade do software Carolus é o cadastro de informações de coleta no banco de dados. Esse cadastro armazena os dados de forma segura e organizada, permitindo a recuperação posterior sem danificar o material coletado, através de consultas no software e consultas via internet, através do site do herbário $(<$ http://www.hvasf.univasf.edu.br/>). Além disso, o cadastro fornece dados para outros componentes do programa, com a geração automática de etiquetas, relatórios, gráficos e mapas temáticos (Fig. 10).

Durante o cadastro, os campos referentes às coletas são preenchidos através de blocos 
Arquivo Editar Exibir Histórico Favoritos Eerramentas Ajüda

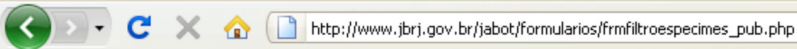

\section{. 8 -}

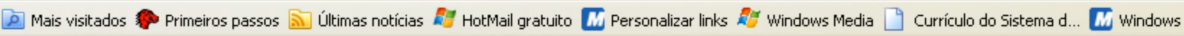

JABOT - Banco de Dados da Flora Bra...

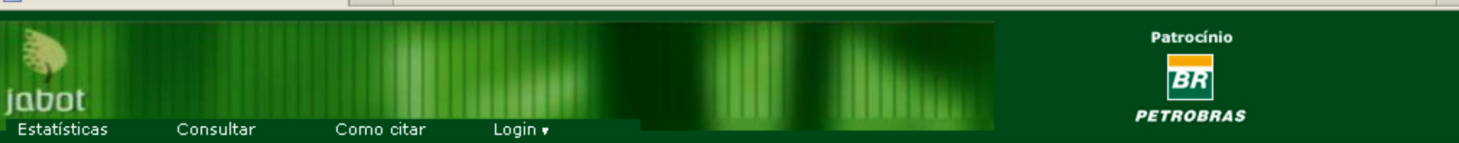

Preencha pelo menos um dos

seguintes campos:

Familia

Gênero

Espécie

Coleçöes Botânicas a serem

consultadas

(Use ctri para selecionar mais de uma, deixe em branco para consultar todas)

RBdna-Banco de DNA/DIPEQ/JBR.J

RBifoto - Fototeca do Herbário do Jardim Botânico do Rio de Janeiro

RB - Herbário do Jardim Botânico do Rio de Janeiro/DIPEQ/JBRJ

RBw - Xiloteca do Jardim Botânico do Rio de Janeiro/DIPEQ/JBR.J

Localidade

Coletor

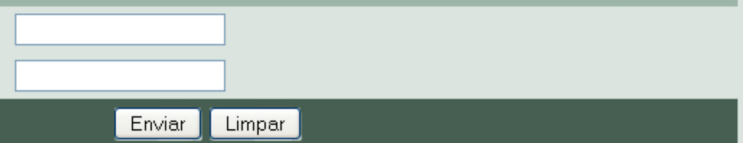

Figura 7 - Sistema de consultas online do Jabot. A consulta pode ser filtrada pelo campos de Família, Gênero, Espécie, Localidade e Coletor, nas diversas bases de dados do RB.

Figure 7-Online queries system of Jabot. The query can be filtered by fields of Family, Genus, Species, locality and collector, in the various databases RB.

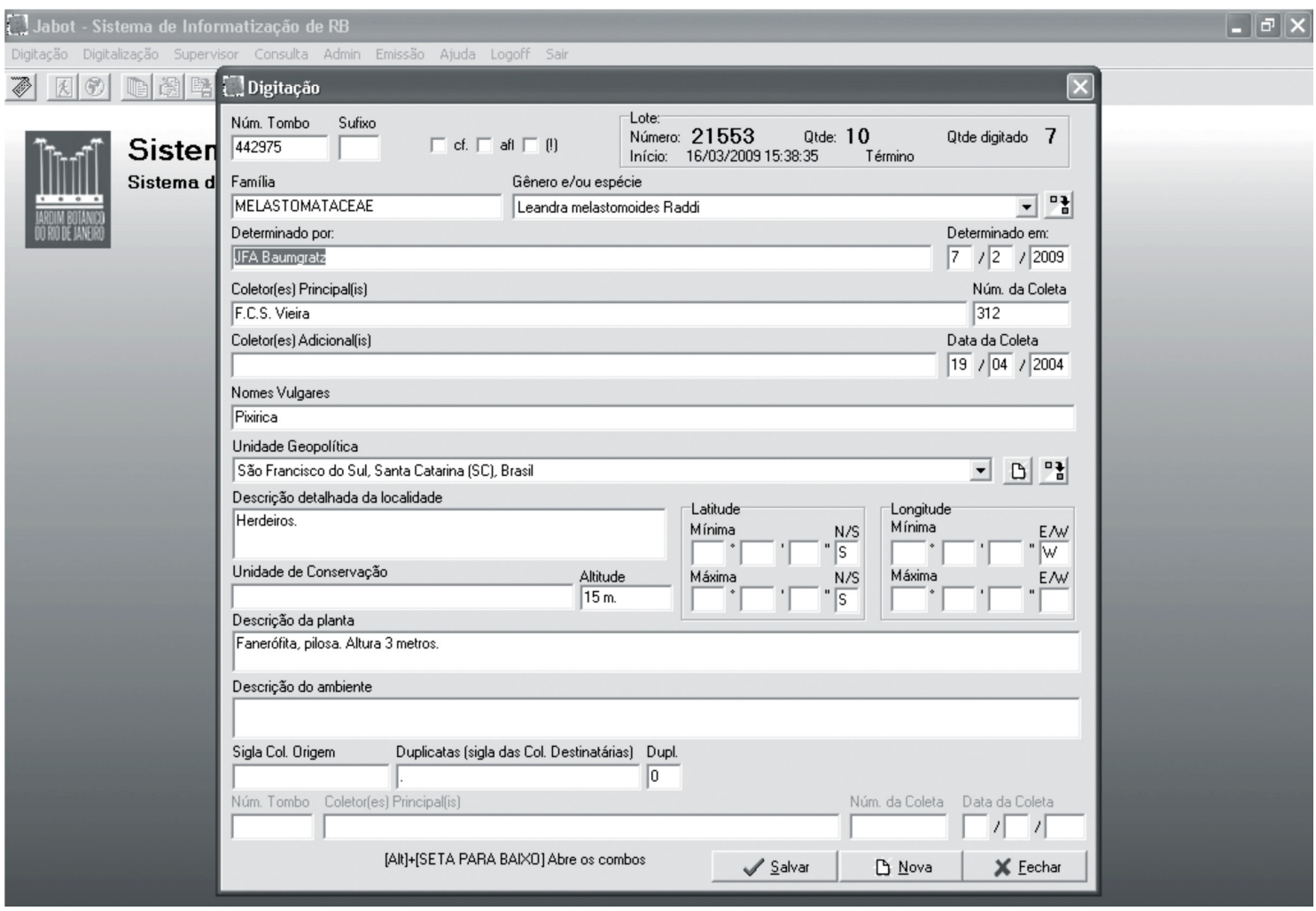

Figura 8 - Janela de entrada de dados do sistema desenvolvido para o projeto de informatização do acervo do Herbário RB. O formulário de cadastro é bastante intuitivo.

Figure 8-Data entry's window developed for RB herbarium's informatization project of its collection. The registration's Form is pretty intuitive. 


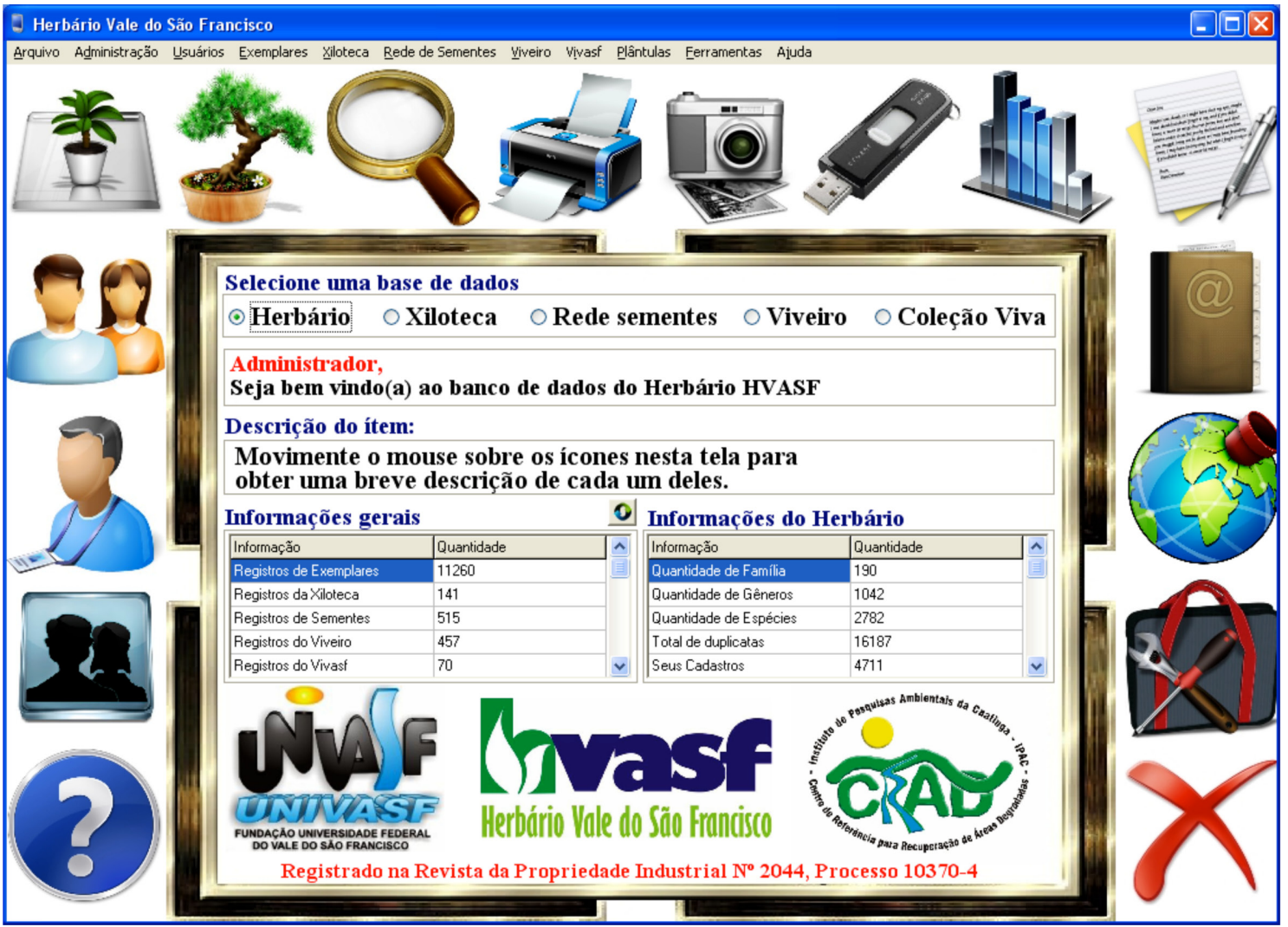

Figura 9 - Tela principal do software Carolus. Cada imagem representa uma funcionalidade, que é indicada por uma descrição facilmente identificável. $\mathrm{O}$ acesso as funcionalidade também pode ser efetuado através do Menu Principal. Os quadros de informações informam o histórico de funcionamento do banco.

Figure 9-Carolus's Main window. Each image represents a feature, which is indicated by an easily identifiable description. The feature's access may also be made through the Main Menu. The tables of information tell the history of the Bank's work.

de múltipla escolha, recursos de autopreenchimento e opções visuais que completam os campos automaticamente, forçando o usuário a digitar o mínimo possível e evitando erros de digitação, muito comuns na digitação de nomes de gêneros, espécies e principalmente de autores. Para isto, foram importados para o Carolus o banco de dados completo publicado na Flora do Brasil (Forzza et al. 2010) composto por 40.982 nomes válidos.

$\mathrm{O}$ banco de imagens integrado ao cadastro permite adicionar fotos de alta resolução, até o tamanho máximo de 20 Megabytes, para cada registro cadastrado, gerando referências únicas das fotos e permitindo consultas ao banco de imagens independente do banco de dados. As fotos representam um recurso complementar de notável importância para identificação do táxon quando são feitas imagens das plantas ainda no campo. Dados como hábito e detalhes de flores, frutos e sementes muitas vezes são perdidas na fotografia da exsicata.

Dentro do formulário de cadastro, informações sobre biomas, solos, tipos vegetacionais e Áreas Prioritárias para Conservação dos biomas brasileiros podem ser preenchidas através de recursos de geoprocessamento que automaticamente atribui o valor correto de cada campo com base nas coordenadas do local de coleta, utilizando mapas vetoriais das revisões mais recentes de nomenclatura no Brasil.

Antes da inserção no banco, os dados passam por uma criteriosa validação, corrigindo erros nomenclaturais das espécies, informações inconsistentes ou chaves duplicadas, como números de coleta repetidos ou tombos idênticos 


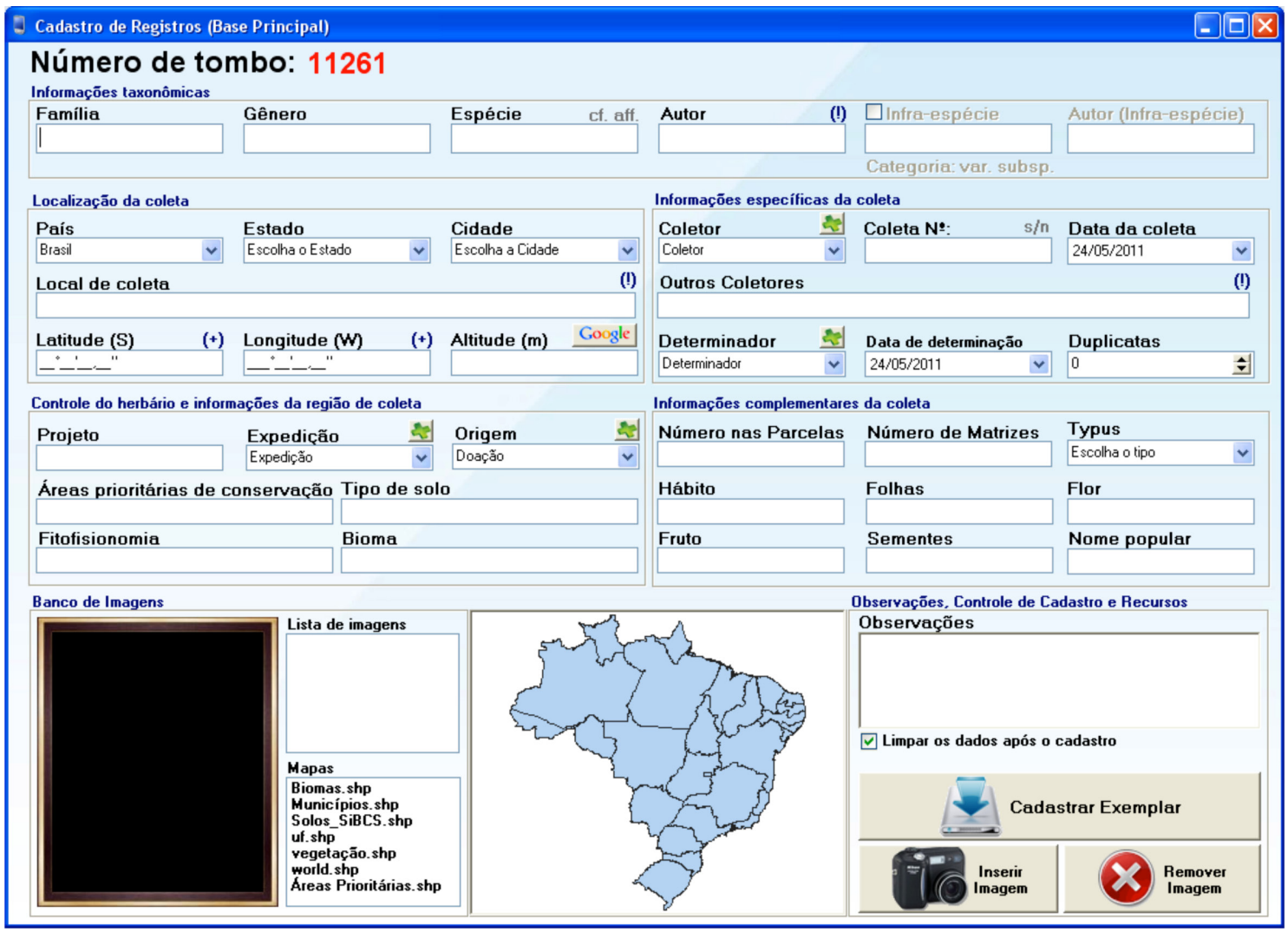

Figura 10 - Formulário para cadastro de registros no Carolus. Todos os campos são de múltiplas escolhas ou oferecem recursos para auto-completar. Neste formulário está integrado um sistema de informações geográficas, que aceita vetores no formato .shp, Banco de imagens, consulta ao Google maps e outros recursos.

Figure 10 - Form for registration of records in the Carolus. All fields are multiple choices or provide resources for auto-completion. This form is an integrated Geographic Information System, which accepts vector format .shp, Images’ database, query to Google Maps and other resources.

para espécies diferentes, fato corriqueiro na maioria das coleções não informatizadas. $\mathrm{O}$ registro cadastrado ainda poderá ter seus dados manipulados de diversas outras formas, como a atualização de campos, consulta de informações, agrupamento de dados ou plotagem e geração de mapas de registros geoprocessados.

A qualidade informacional das etiquetas de um herbário é um ponto tão importante quanto à própria coleta. As informações contidas nas etiquetas permitem, por exemplo, a obtenção de informações do exemplar em sua formação natural, que normalmente são perdidas quando a planta é desidratada. Digitar ou escrever tais etiquetas é uma das tarefas mais demoradas e propícias a erros dentro de qualquer herbário. Para superar este problema, o software Carolus gera etiquetas customizáveis dos dados cadastrados, possibilitando a geração em poucos segundos de milhares de etiquetas, com informações padronizadas, sem erros de formatações e diminuindo ao máximo as falhas de digitação. Para gerar uma etiqueta, o usuário acessa o formulário de geração, seleciona as etiquetas desejadas e clica no botão de geração. Como resultado, as etiquetas prontas para impressão são exibidas, permitindo salvar ou exportar para vários formatos (Fig. 11).

Dados de exemplares cadastrados podem contribuir para a geração de estatísticas descritivas no software, as quais podem ser concebidas como um recurso visual aplicado à tomada de decisões rápidas e fundamentada em dados. Com base nos gráficos apresentados, o curador tem acesso a dados concretos e atuais da dinâmica do herbário, podendo decidir 


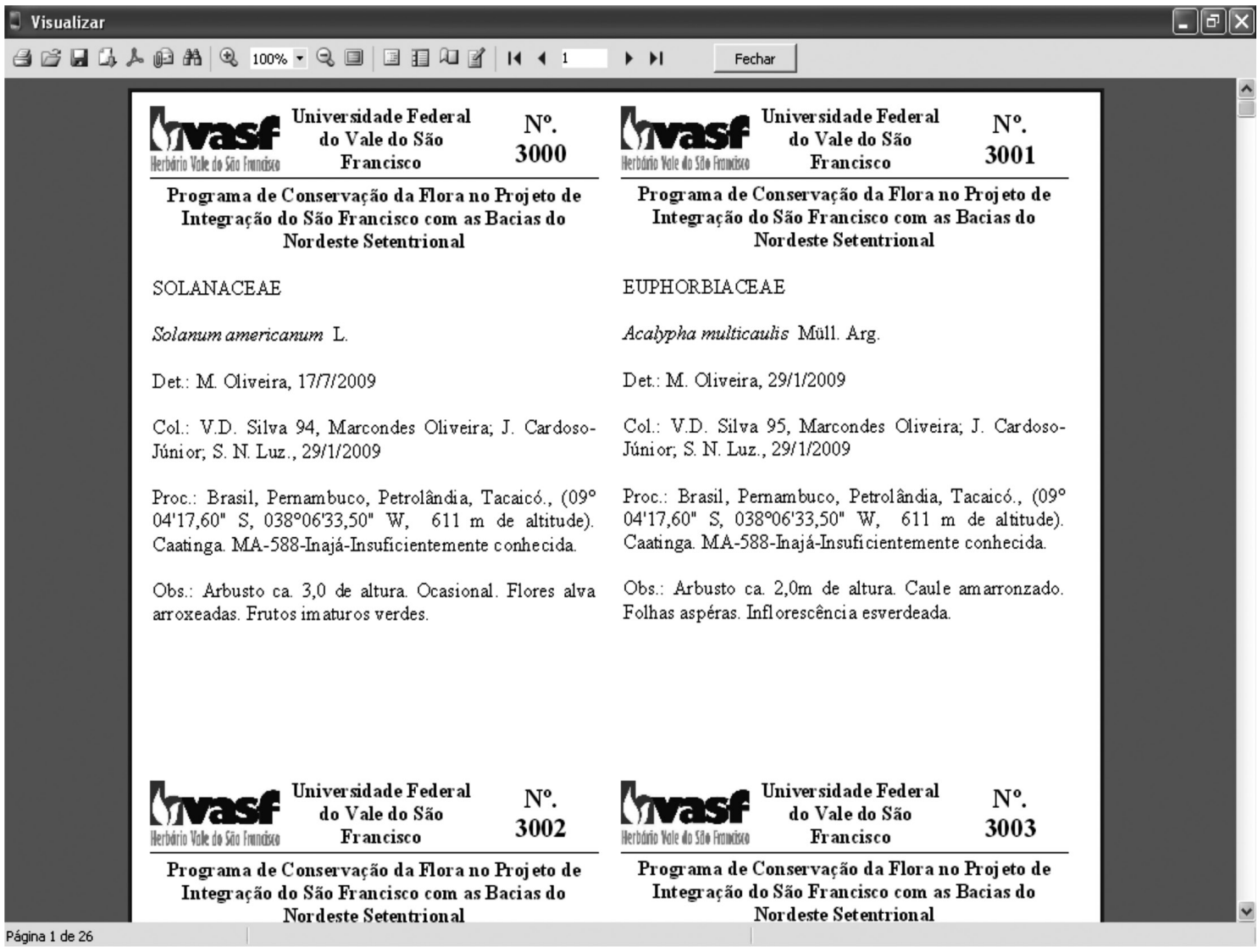

Figura 11 - Formulário com as etiquetas geradas pelo software Carolus. O usuário informa os números das etiquetas desejadas, o cabeçalho, o rodapé e os textos adicionais e tem como resultado etiquetas padronizadas. É possível exportar os resultados para diversos formatos, como.PDF ou .DOC.

Figure 11 - Form with labels generated by the software Carolus. The user types the numbers of the desired records, header, footer, and additional text and results standardized labels. You can export the results to various formats, such as .PDF or .DOC.

estratégias de manejo de herbário com base nestes gráficos. É possível ainda a geração de vários tipos de gráficos e a formatação de qualquer elemento em exibição, como legendas, barras, cores e marcações (Fig. 12).

$\mathrm{O}$ aplicativo aqui descrito fornece um conjunto de relatórios para todos os dados presentes nas tabelas da base de dados, restando para o usuário a formatação desejada das informações, que poderá ser feita através de duas ou três ações complementares. Por mais robusto que um sistema seja, e por mais recursos que ele proporcione, este será inútil se usuário não for capaz de recuperar as informações cadastradas de maneira que os usuários possam entender e utilizar tais informações. O software Carolus proporciona vários tipos de pesquisa e ferramentas de auxílio a consultas, nas quais é possível filtrar qualquer campo por diversas restrições e realizar pesquisas de qualquer complexidade, que retornarão somente os campos e os registros desejados pelo usuário. Após a exibição da pesquisa, o software calcula automaticamente a quantidade de famílias, gêneros e espécies distintas que apareceram na busca, além de agrupar qualquer outra informação que o usuário deseje, como por exemplo, em quais cidades ocorreram as coletas, sem repetição de campo.

Os sistemas de consulta também permitem fazer buscas de qualquer complexidade, como exibir a relação de Famílias $\mathrm{X}, \mathrm{Y}$ e $\mathrm{Z}$ que não sejam coletadas nas cidades A, B e C e que tenham características $\mathrm{D}, \mathrm{E}$, mas não $\mathrm{F}$, exportando os 


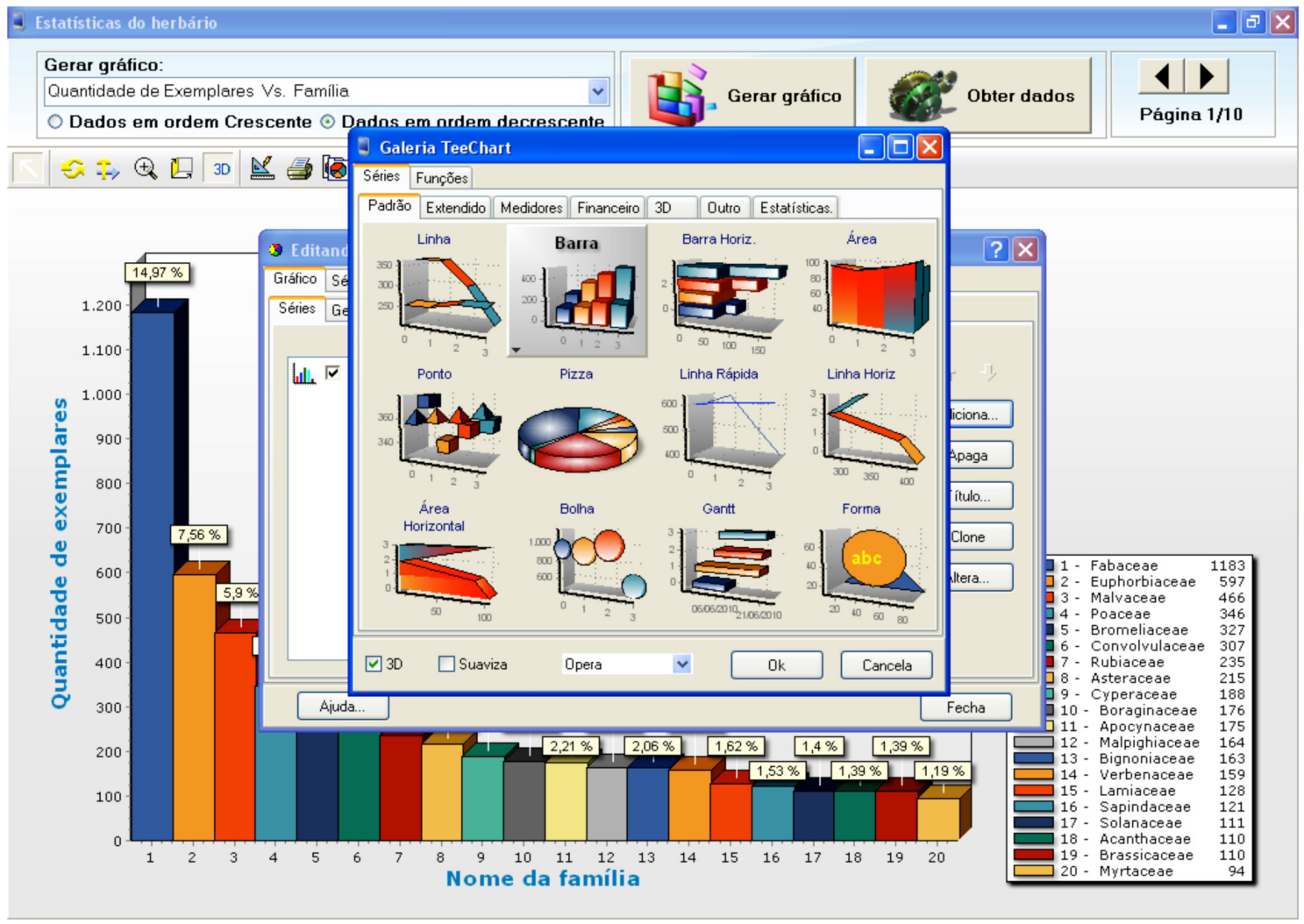

Figura 12 - Formulário de geração de gráficos do Carolus. Vários tipos de gráficos, 2D e 3D, estão disponíveis. Todos os elementos do gráfico podem ser formatados. A aquisição de dados é realizada por consultas e agrupamentos, gráficos pré-formatados ou inserção manual de dados.

Figure 12 - Statistics Generation's Form of Carolus. Several kinds of graphics are available, in 2D and 3D. All chart elements can be formatted. Data acquisition is performed by groups and consultations, pre-formatted charts or manual data entry.

dados ao final da pesquisa, gerando etiquetas dos dados exibidos, ou mapa dos pontos de coleta com alta precisão. Além destas consultas, no qual um ou mais campos são filtrados por diversos valores, é possível realizar buscas diretamente em SQL (Structured Query Language). A Figura 13 ilustra uma consulta simples, no qual o campo família é a Fabaceae, estado de coleta é limitado à Pernambuco e apenas alguns campos são desejados. O resultado foi ordenado por número de tombo.

A fim de auxiliar o cadastro de dados e a visualização das informações como um todo, o programa aqui descrito possui recursos para tratar dados espacialmente explícitos, no qual o usuário fornece mapas ou vetores em formatos comuns às ferramentas que fazem este tipo de análise, como software ArcGis ${ }^{\circledR}$ (Esri 2009), e estes mapas serão utilizados para troca de informações com o banco de dados.
O Carolus acompanha um conjunto de mapas que lhe permitem verificar se as coordenadas digitadas no momento de cadastro corresponde às cidades informadas, ou autocompletar os dados de biomas brasileiros (IBGE 2002a-c), classificação de solos (IBGE 2006), tipos vegetacionais (MMA 2006) e áreas prioritárias para a conservação da biodiversidade (MMA 2004) para todos os registros. Ao abrir um mapa de solos com uma classificação atual, pode-se solicitar ao Carolus que ele modifique todas as informações anteriormente cadastradas do campo solos para uma nova classificação presente no arquivo vetorial. Os mapas cadastrados podem ser utilizados para distribuição de dados e plotagem de informações, bem como a geração de mapas temáticos (Fig. 14). Os recursos para tratamento espacial integrado ao Carolus estão associados aos 


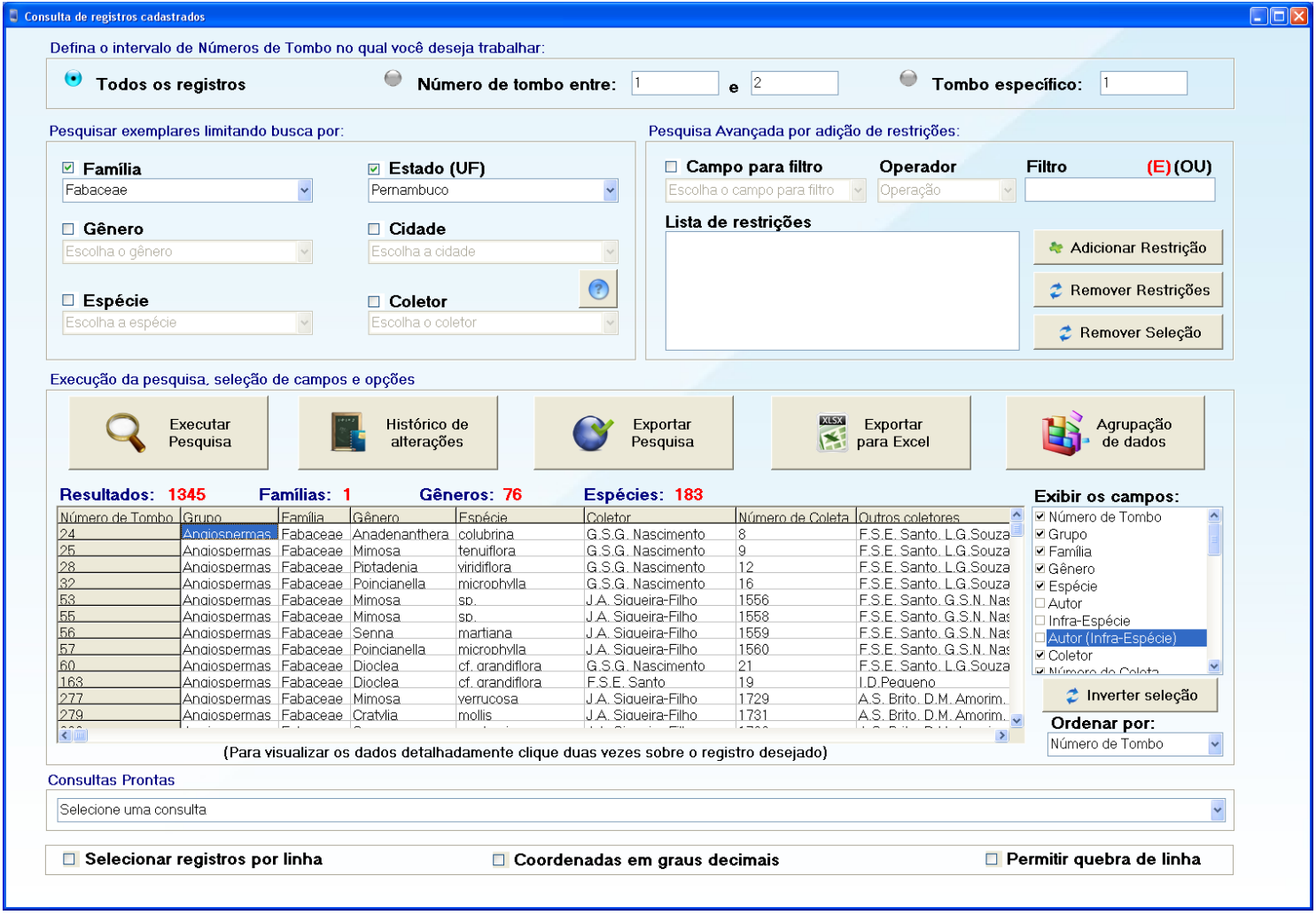

Figura 13 - Exemplo de consulta por restrição de campos no Carolus. Os campos família e estado foram utilizados com filtro para a família Fabaceae e o estado Pernambuco. Ao lado da tabela de resultados estão os campos que são exibidos na pesquisa e o campo de ordenação, que neste exemplo é o número de tombo.

Figure 13 - Example of query by restriction of fields in Carolus. Fields family and state were used to filter the Fabaceae family and the Pernambuco's province. Alongside the results table are the fields that are displayed in the search field and sorting, which in this example is the number of fall.

formulários de cadastro, consulta e atualização de dados. Com isso, é possível se comunicar com o formulário de consultas e utilizar, por exemplo, um mapa de Biomas e solicitar ao software que plote em um determinado mapa, os pontos de todas as coletas do estado da Bahia (Fig. 13).

A análise espacial do dados exige a digitação precisa de informações sobre espécies e coordenadas nos softwares para utilização no SIG's, com amplas possibilidades de erros e consequentemente, falhas na interpretação dos dados. O software Carolus simplifica e possibilita uma análise com segurança, convertendo as cooordenadas cartesianas para graus decimais e exportando os dados de uma só vez para o SIG garantindo a fidelidade dos dados originais.

Para aumentar a confiabilidade e flexibilidade software, o usuário pode importar e exportar dados para diferentes formatos, como .xls, .sql, .xml, .txt, .html. Qualquer um destes formatos poderá ser utilizado para geração de backup da base de dados. Outra possibilidade é a exportação de dados no padrão internacional Darwin Core - um corpo de normas que inclui um glossário de termos (campos ou atributos), destinado a facilitar o compartilhamento de informações sobre a diversidade biológica, fornecendo definições de referência, exemplos e comentários $(<\mathrm{http}: / / \mathrm{rs} . t d w g$.org/dwc/index. htm>). O padrão Darwin Core é utilizado, por exemplo, pelo Centro de Referência em Informação Ambiental (CRIA), que em parceria com o Jardim Botânico do Rio de Janeiro, publicou a Flora do Brasil (Forzza et al. 2010) que permite atualizações periódicas das coleções botânicas de todo o país (<http://www.cria.org.br/>). 


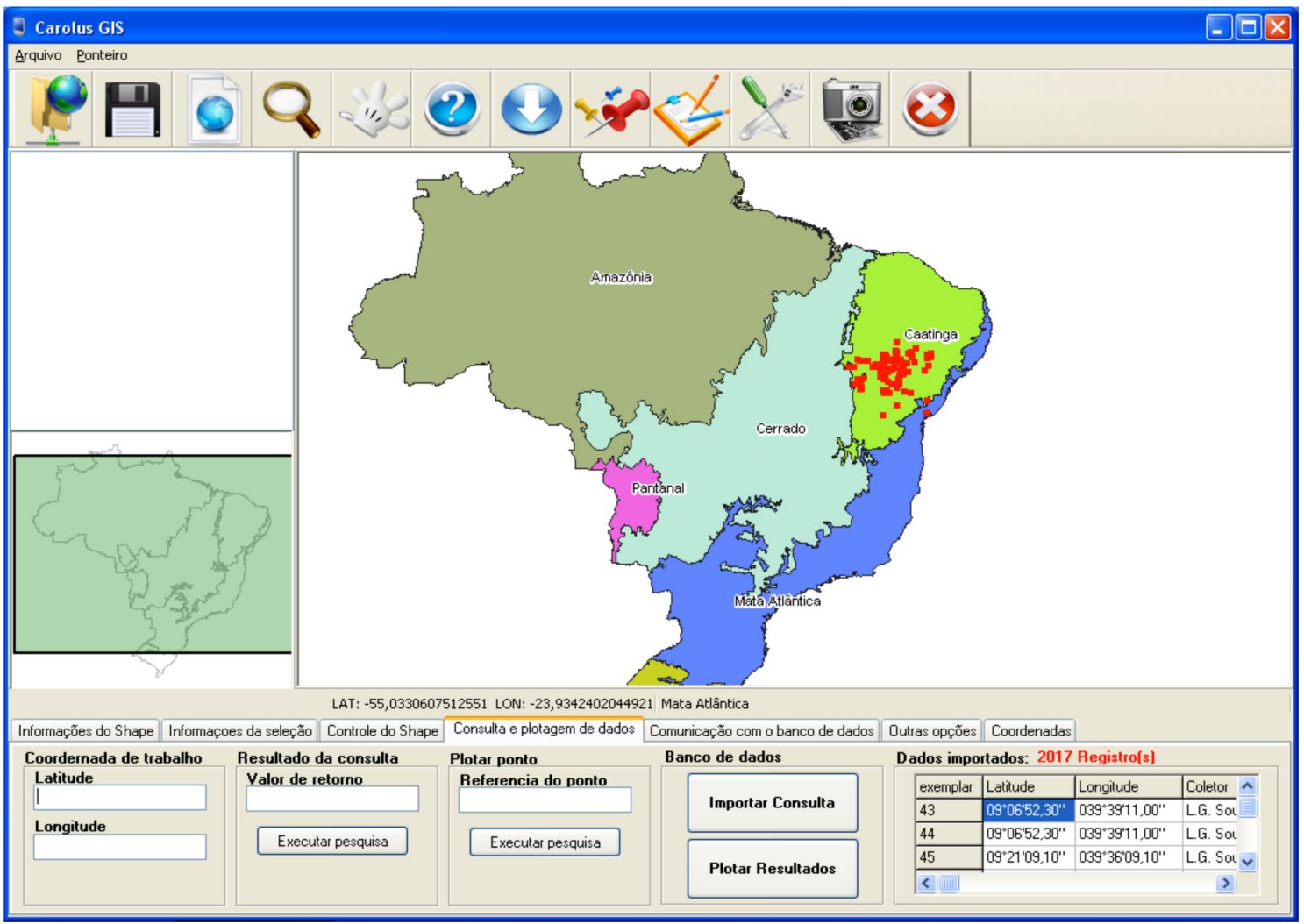

Figura 14-Plotagem de coletas da Bahia em um Shape de biomas brasileiros. Inicialmente uma consulta foi executada, restringindo os resultados para ao estado da Bahia. Logo em seguida, selecionou-se um mapa de biomas, importou-se a consulta e plotou-se os registros em forma de pontos. Com isso é possível atribuir ao campo Bioma os valores dos pontos aos registros consultados.

Figure 14-Plot of collections of Bahia in a shape of biomes. Initially, a query was performed, restricting the results to the state of Bahia. Shortly thereafter, selected a shape of biomes, the query was imported and the records are plotted at shape of points. Through this resource it's possible assign the biome field's values to the records consulted.

A integração com recursos online estão presentes no software através de ferramentas disponibilizadas na internet e que são imprescindíveis aos profissionais de botânica, especialmente os taxonomistas, como visualização das coletas no Google Maps (<http://maps.google.com.br/>), consultas automáticas de autores no International Plant Name Index (<http://www.ipni.org/>) e Flora do Brasil (<http://floradobrasil.jbrj.gov.br/2010/>), atualização da lista de localidades do Brasil e informações geográficas em geral através do site do Instituto Brasileiro de Geografia e Estatística (<http://www.ibge.gov.br/>), entre outras funcionalidades.

Com intuito de orientar os esforços em campo foi desenvolvido, através da linguagem C\#, uma versão mobile do aplicativo, para
Palms Pocket PC e Smartphones com Windows Mobile 5 (Deitel \& Deitel 2003), possibilitando armazenar os registros no momento da coleta e consultar a base de dados offline. Os arquivos gerados pelo Palm, no formato XML (eXtensible Markup Language), são diretamente importados para o servidor de banco de dados. A base de dados offline do Palm é gerada automaticamente pelo software Carolus, garantindo dados atualizados e no padrão do Palm.

Como todos os dados ficam armazenados em um servidor remoto, estes podem ser lidos diretamente de uma página web, fornecendo atualização em tempo real a todos os usuários que acessam a página do herbário HVASF $(<$ http://www.hvasf.univasf.edu.br/>). A página tem uma interface fácil que permite filtros e consultas em base de dados específica, além da 


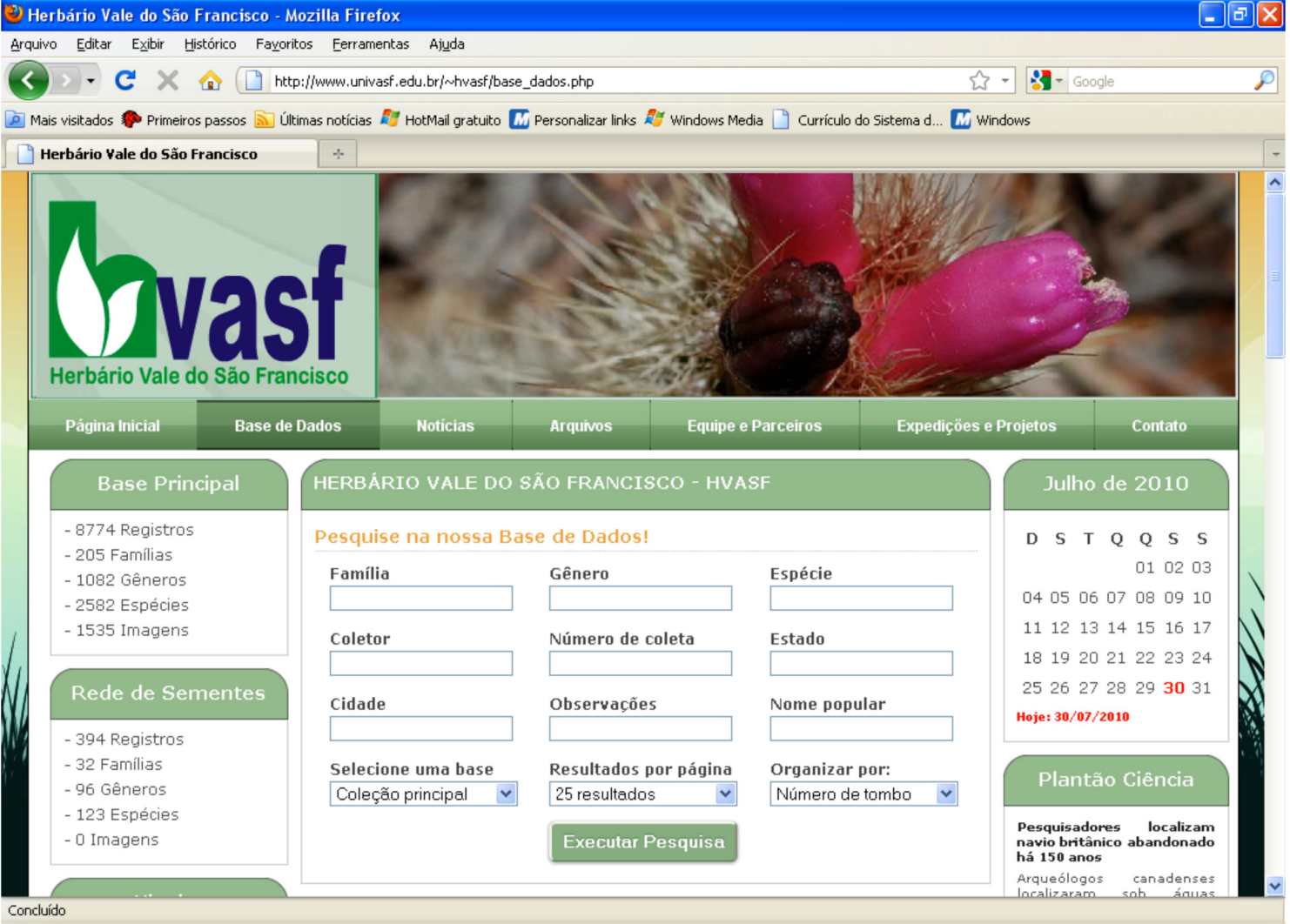

Figura 15 - Sistema de consultas online do Carolus. A consulta pode ser filtrada pelos campos de Família, Gênero, Espécie, Coletor, Número de coleta, Estado, Cidade, Observações da espécie e Nome popular nas diversas bases de dados do herbário HVASF.

Figure 15 - Online query system of Carolus. The query can be filtered by fields of Family, Genus, Species, Collector, Collection Number, State, City, comments on the species and the popular name in different databases of the HVASF herbarium.

ordenação de resultados e exportação para Excel (Fig. 15).

As características tratadas anteriomente são os recursos básicos do Sistema Carolus que são estendidas para todos os seus módulos: o Herbário, a Xiloteca, a Carpoteca e as Coleções Vivas. O software está em fase de ajustes finos, buscando o constante desenvolvimento, melhorias e adição de ferramentas, com o objetivo de fornecer ferramentas modernas de manipulação eletrônica no gerenciamento e manejo de coleções botânicas.

A utilização de um sistema de banco de dados integrado ao banco de imagens e associado a um conjunto de informações oficiais do IBGE (2002a-c, 2006), Ministério do Meio Ambiente (MMA 2004, 2006) confere maior credibilidade a determinação do táxon, fomentando um intercambio de conhecimento botânico sobre as espécies cadastradas e gerando informações confiáveis para pesquisadores e trabalhos de diversas naturezas.

Adicionalmente, os novos registros para um determinado bioma ou estado também são detectados imediatamente. No Herbário HVASF, por exemplo, ocorrem 436 novos registros de espécies para a Caatinga o que representa uma relevante contribuição para a Flora do Brasil, diminuindo a anemia intitucional ainda vigente na região (Santos et al. 2011).

A aplicabilidade do Carolus não se restringe ao universo taxonômico ou gerenciamento de um herbário, mas apresenta possibilidades concretas de aplicação em várias áreas da Botânica ou Ecologia. Assim, análises mais críticas sobre a flora de uma determinada região são importantes para auxiliar a tomada de decisões no planejamento e implementação de 
unidades de conservação baseado em um conjunto florístico particular, apontando endemismos e espécies ameaçadas. Tais análises também permitem direcionar inventários florísticos em áreas prioritárias para a conservação da biodivesidade, como preconizado pelo MMA (2002), preencher lacunas conhecimento em áreas insuficientemente inventariadas, análises biogeográficas, detectar processos de invasão biológica, modelagens sobre distribuição realizada e potencial, assim como sugerir espécies para restauração de áreas que serão modificadas por megaempreendimentos, à exemplo de hidroelétricas, ferrovias e rodovias, que são obrigados por força de lei de elaborar e implementar Planos de Recuperação de Áreas Degradadas (PRAD's) com as espécies nativas de uma dada região (Siqueira Filho, 2012).

Assim, acreditamos que o Carolus possui os atributos e requisitos necessários para amplo uso nos herbários das instituições brasileiras sob os aspectos da versatilidade, qualidade e precisão de informações, agilidade no processamento de dados e gratuidade no seu uso que permitirão o amplo acesso dos pesquisadores ao conhecimento da biodiversidade nacional.

\section{Agradecimentos}

Ao CNPq, pela concessão da bolsa de estudo do primeiro autor; aos botânicos André Paviotti Fontana, Jéssica Viviane Amorim, Jefferson Rodrigues Maciel, Macielle Macedo Coelho, Marcondes Albuquerque de Oliveira, Marcos Vinicius Meiado e Maria Jaciane de Almeida Campelo, todos do CRAD/UNIVASF, por todo o apoio e suporte técnico oferecidos durante o desenvolvimento do programa Carolus; aos revisores anônimos pelas correções e sugestões.

\section{Referências}

About PostgreSQL. Disponível em <http://www. postgresql.org/about/>. Acessado em 20 Jan 2010.

Barbosa, M.R.V. \& Peixoto, A.L. 2003. Coleções botânicas brasileiras: situação atual e perspectivas. Coleções biológicas de apoio ao inventário, uso sustentável e conservação da biodiversidade. Instituto de Pesquisas Jardim Botânico do Rio de Janeiro, Rio de Janeiro. Pp. 113-125.

Biodiversity Information Standards TDWG. Disponível em $<$ http://rs.tdwg.org/dwc/index. htm>. Acesso em 04 Set 2011.

BRAHMS - Botanical Research And Herbarium Management System. Disponível em $<$ http://dps. plants.ox.ac.uk/bol/>. Acesso em 04 Set 2011.
Centro de Referência em Informação Ambiental. Disponível em < http://www.cria.org.br/>. Acesso em 04 Set 2011.

Deitel, H.M. \& Deitel, P.J. 2001. C++: Como programar? 3 ed. Bookman, Porto Alegre. 1173p.

Deitel, H.M. \& Deitel, P.J. 2003. C\#: Como Programar? 1 ed. Makron Books, São Paulo. 1153p.

ESRI. (2009). ArcGIS 9.2. Disponível em <http:// webhelp.esri.com/arcgisdesktop/9.2>. Acesso em 29 Set 2011.

Forzza, R.C.; Leitman, P.M.; Costa, A.F.; Carvalho Jr., A.A.; Peixoto, A.L.; Walter, B.M.T.; Bicudo, C.; Zappi, D.; Costa, D.P.; Lleras, E.; Martinelli, G.; Lima, H.C.; Prado, J.; Stehmann, J.R.; Baumgratz, J.F.A.; Pirani, J.R.; Sylvestre, L.; Maia, L.C.; Lohmann, L.G.; Queiroz, L.P.; Silveira, M.; Coelho, M.N.; Mamede, M.C.; Bastos, M.N.C.; Morim, M.P.; Barbosa, M.R.; Menezes, M.; Hopkins, M.; Secco, R.; Cavalcanti, T.B. \& Souza, V.C. 2010. Lista de espécies da flora do Brasil. Jardim Botânico do Rio de Janeiro. 871p.

Google Maps. Disponível em $<$ http://maps.google.com. br/>. Acesso em 13 Fev 2010.

Gonzalez, M. 2009. Quantificação de custo e tempo no processo de informatização das coleções biológicas brasileiras: a experiência do herbário do Instituto de Pesquisas Jardim Botânico do Rio de Janeiro. Rodriguésia 60: 711-721.

Heywood, V.H. 2001. Floristics and monography - an uncertain future? Taxon 50: 361-380.

Heuser. C.A. 2009. Projeto de Banco de Dados. 6 ed. Editora Bookman, Porto Alegre. 282 p.

IPNI - The International Plant Names Index. Disponível em < http://www.ipni.org/> . Acesso em 13 Fev 2010.

IBGE - Instituto Brasileiro de Geografia e Estatística. Disponível em < http://www.ibge.gov.br/home/>. Acesso em 13 Fev 2010.

IBGE - Instituto Brasileiro de Geografia e Estatística. 2002a. Brasil Milionésimo. Biomas Brasileiros. Disponível em <http://mapas.ibge.gov.br/biomas2/ viewer.htm>. Acesso em 13 Fev 2010.

IBGE - Instituto Brasileiro de Geografia e Estatística. 2002b. Brasil Milionésimo. Municípios Brasileiros. Disponível em <http://mapas.ibge.gov.br/divisao/ viewer.htm>. Acesso em 13 Fev 2010.

IBGE - Instituto Brasileiro de Geografia e Estatística. 2002c. Brasil Milionésimo. Estados Brasileiros. Disponível em <http://mapas.ibge.gov.br/divisao/ viewer.htm>. Acesso em 13 Fev 2010.

IBGE - Instituto Brasileiro de Geografia e Estatística. 2006. Novo Sistema Brasileiro de Classificação de Solos (SBCS). Disponível em $<$ http://mapas.ibge. gov.br/solos/viewer.htm>. Acesso em 13 Fev 2010.

MMA - Ministério do Meio Ambiente. 2002. Biodiversidade brasileira: avaliação e identificação de áreas e ações prioritárias para a conservação, utilização sustentável e repartição de benefícios 
da biodiversidade brasileira. Ministério do Meio Ambiente, Brasília. 404p.

MMA - Ministério do Meio Ambiente. 2004. PROBIO. Áreas Prioritárias para Conservação. Disponível em <http://mapas.mma.gov.br/mapas/aplic/probio/ datadownload.html >. Acesso em 13 Fev 2010.

MMA - Ministério do Meio Ambiente. 2006. PROBIO. Tipos Vegetacionais da Caatinga. Disponível em $<$ http://mapas.mma.gov.br/mapas/aplic/probio/ datadownload.html >. Acesso em 13 Fev 2010.

MMA - Ministério do Meio Ambiente. 2009. Disponível em $<$ http://mapas.mma.gov.br/i3geo/datadownload. htm $>$. Acesso em 01 Fev 2009.

JABOT. Disponível em < http://www.jbrj.gov.br/jabot/> Acesso em 28 Jul 2010.

Lista de Espécies da Flora do Brasil. 2012. Lista de espécies da flora do Brasil. Disponível em: $<$ http://floradobrasil. jbrj.gov.br/2012>. Acesso em 13 Fev 2012.

Peixoto, F.L. 2005. O processo de informatização de herbários: estudo de caso. Dissertação de Mestrado. Escola Nacional de Botânica Tropical, Rio de Janeiro. 69p.

Peixoto, A.L.; Barbosa, M.R.V.; Canhos, D.A.L. \& Maia, L.C. 2009. Coleções botânicas: objetos e dados para a ciência. In: Granato, M. \& Rangel, M. (orgs.). Cultura material e patrimônio da Ciência e Tecnologia. Museu da Astronomia e Ciências Afins, Rio de Janeiro. Pp. 6-10.

Pressman, R.S. 2002. Engenharia de Software. 5 ed. McGraw-Hill, Rio de Janeiro. 843p.

Rede Brasileira de Herbários. Disponível em <http:// www.botanica.org.br/conteudo_herbarios.php $>$. Acesso em 13 Fev 2010.
Roeldes, A.; Moreira, G.; Domingues, L. \& Cardoso, A. 2009. A Importância de um Sistema de Banco de Dados. Compilação de apoio ao ensino. Biblioteconomia. Universidade Federal do Espírito Santo (UFES). Disponível em < http://www.scribd. com/doc/18097773/A-Importancia-de-um-Sistemade-Banco-de-Dados>. Acesso em 10 Out 2010.

Santos, J.C.; Leal, I.R.; Almeida-Cortez, J.S.; Fernandes, G.W. \& Tabarelli, M. 2011. Caatinga: the scientific negligence experienced by a dry tropical Forest. Tropical Conservation Science 4: 276-286.

Schatz, G.E. 2002. Taxonomy and herbaria in service of plant conservation: lessons from Madagascar's endemic families. Annals of the Missouri Botanical Garden 89: 145-152.

Silberschatz, A.; Korth, H.F. \& Sudarshan, S. 1999. Sistema de banco de dados. 3 ed. Makron Books, São Paulo. 778p.

speciesLink. Disponível em <http://splink.cria.org.br/ project?criaLANG=pt $>$. Acesso em 04 Set 2011.

Siqueira, A.A.; Santos-Filho, J.V. \& Siqueira-Filho, J.A. 2010. Software Carolus: Revista da Propriedade Industrial $N^{\circ}$ 2044. Processo 10370-4.

Siqueira Filho, J. A. 2012. Flora das caatingas do Rio São Francisco: história natural e conservação. Andrea jakobsson Estúdio Editorial, Rio de Janeiro, 552 p.

Teixeira, A.L.A.; Moretti, E. \& Christofoletti, A. 1992. Introdução ao Sistema de Informação Geográfica. Ed. do Autor, Rio Claro. 80p.

Walters, S.M. 1993. Herbaria in the 21st century: Why should they survive? Webbia 48: 673-387. 